This is a repository copy of. "Adaptive UKF-based model predictive control of a Fresnel collectorfield. in the Depósito de Investigación de la Universidad de Sevilla

Version: Author Accepted Version

Citation: Antonio J Gallego, Adolfo J. Sánchez, M, Berenguel \& Eduardo F. Camacho. Adaptive UKF-based model predictive control of a Fresnel collectorfield. Journal of Process Control - ISSN 0959-1524. Vol. 85, pp. 76-90. Enero 2020. 10.1016/j.jprocont.2019.09.003

To cite this publication, please use the final published version (if applicable). Please check the document version above.

Copyright: Other than for strictly personal use, it is not permitted to download, forward or distribute the text or part of it, without the consent of the author(s) and/or copyright holder(s), unless the work is under an open content license such as Creative Commons.

Takedown policy: Please contact us (idus@us.es) and provide details if you believe this document breaches copyrights. We will remove access to the work immediately and investigate your claim 


\title{
Adaptive UKF-based Model Predictive Control of a Fresnel Collector Field
}

\author{
Antonio J. Gallego ${ }^{1}$, Adolfo J. Sánchez ${ }^{1}$, M. Berenguel ${ }^{\text {b }}$, Eduardo F. Camacho ${ }^{1}$ \\ ${ }^{a}$ Departamento de Ingeniería de Sistemas y Automática, Universidad de Sevilla, Camino de los Descubrimientos s/n., 41092 Sevilla, Spain \\ ${ }^{b}$ Centro Mixto CIESOL, ceiA3, Departamento de Informática, Universidad de Almería. Ctra. Sacramento s/n, 04120, Almería, Spain
}

\begin{abstract}
One of the ways to improve the efficiency of solar energy plants is by using advanced control and optimization algorithms. In particular, model predictive control strategies have been applied successfully in their control.

The control objective of this kind of plant is to regulate the solar field outlet temperature around a desired set-point. Due to the highly nonlinear dynamics of these plants, a simple linear controller with fixed parameters is not able to cope with the changing dynamics and the multiple disturbance sources affecting the field.

In this paper, an adaptative model predictive control strategy is designed for a Fresnel collector field belonging to the solar cooling plant installed at the Escuela Superior de Ingenieros in Sevilla. The controller changes the linear model used to predict the future evolution of the system with respect to the operating point.

Since only the inlet and outlet temperatures of the heat transfer fluid are measurable, the intermediate temperatures have to be estimated. An unscented Kalman filter is used as a state estimator. It estimates metal-fluid temperature profiles and effective solar radiation.

Simulation results are provided comparing the proposed strategy with a PID+feedforward series controller showing better performance. The controller is also compared to a gain scheduling generalized predictive controller (GS-GPC) which has previously been tested at the actual plant with a very good performance. The proposed strategy outperforms these two strategies.

Furthermore, two real tests are presented. These tests show that the proposed controller achieves adequate set-point tracking in spite of strong disturbances.
\end{abstract}

Keywords: Solar Energy, Fresnel, Model Predictive Controller, Kalman Filter

\section{Introduction}

The great impulse experienced by renewable energy systems is driven by the need of reducing the negative environmental impact that fossil fuels produce. Particularly, solar energy is the most abundant renewable energy source. The only limitation of the use of solar thermal energy is harnessing it in an efficient and costeffective way $[1,2]$. Other solar technologies such as photovoltaics (PV) are a very low-cost alternative, but the difficulty is storing electrical energy which is more difficult and expensive than storing thermal energy [3].

Solar energy has multiple applications such as electricity generation or solar cooling systems. The use of

Email addresses: gallegolen@ hotmail . com (Antonio J. Gallego), beren@ual.es (M. Berenguel), ef camacho@us.es (Eduardo F. Camacho)

URL: adolfo.spf@gmail . com (Adolfo J. Sánchez)

${ }^{1}+34954487347$

Preprint submitted to Journal of Process Control solar energy for electricity production has been widely extended in the last 15 years. A solar thermal plant consists of a solar field which heats up a fluid and then powers a steam generator to produce electricity. Examples of solar thermal energy plants are the SOLANA and Mojave Solar parabolic trough plants constructed in Arizona and California, each with a power production of $280 \mathrm{MW}[4,5]$. The $50 \mathrm{MW}$ CSP plant of Yumen can be cited as a more recent solar trough plant [6]. For further information concerning the solar energy plants commissioned or currently under construction, the reader is referred to [7].

The use of solar energy for cooling systems has been increasing for several decades, spurred by the fact that the need for air conditioning is usually well correlated to high levels of solar radiation [8, 9]. The plant used in this paper as a test-bench for control purposes is the solar cooling plant located on the roof of the Escuela Superior de Ingenieros (ESI) in Seville [10]. The 
plant consists of a Fresnel collector field, a double effect $\mathrm{LiBr}+$ water absorption chiller and a storage tank. The Fresnel collector delivers pressurized water to the absorption machine for producing air conditioning. If solar radiation is not high enough for heating the water up to the required temperature, the storage tank can be used. If neither the solar field nor the storage tank are able to heat the water up to the operation temperature, the absorption machine uses natural gas.

Usually, the control goal in solar energy plants is to regulate the solar field outlet temperature around a set-point [11]. Many works related to the control of solar plants have been developed and published since 1980. Most of them were tested in the parabolic trough ACUREX solar collector field. In [12], a review of different control strategies applied to the ACUREX plant is presented. Moreover, the books by Camacho and coworkers [13] and Lemos and co-workers [14] provide an overview of different approaches related to predictive and adaptive control applied to this kind of system.

The regulation of the outlet temperature of a solar field around a set-point is hindered by the effect of multiple disturbance sources and its dynamics are greatly affected by the operating conditions [15]. This fact means that conventional linear control strategies do not perform well throughout the entire range of operations. In general, adaptative, robust or nonlinear schemes are needed to cope with the changing dynamics of a solar field. In [16] a practical nonlinear MPC is developed. More recently, in [17] a nonlinear continuous time generalized predictive control (GPC) is developed and tested by simulation. In [18], an improvement of a Gain Scheduling Model Predictive controller is proposed and tested on a model of the ACUREX solar field.

The development of control strategies for Fresnel collector fields has not been as popular as for parabolic trough fields. As examples, in [19], control approaches for this kind of plant are discussed. The application of an explicit model predictive control is also tested by simulation. In [20] a sliding model predictive control based on a feedforward compensation is developed for a Fresnel collector field and tested on a nonlinear model of a Fresnel collector field. In [21], control systems for direct steam generation in linear concentrating power plants are investigated. In [22], control laws for linear Fresnel plants have been developed. In [23] a Gain Scheduling Generalized Predictive Controller was developed and tested for a Fresnel collector field.

In this paper an adaptative model predictive control (MPC) strategy is applied to the Fresnel solar collector field. The MPC strategy uses a state-space formulation whose linear matrices are obtained by linearizing a nonlinear distributed parameter model of the field. The non-measurable states are estimated using an unscented Kalman filter (UKF) [24]. Many examples of the use of the UKF as a state estimator when controlling solar energy systems can be found in literature. In [25], a discrete-time adaptative scheme for temperature control in molten-salt solar collector-fields is proposed. In [26], a neural model-based MPC strategy using a UKF for estimating the weights and biases was tested on the actual ACUREX solar field. In [27], an iterative extended Kalman filter is used to estimate the states and solar radiation for control purposes. It was tested by simulation for a model of the Shiraz solar plant. Regarding solar cooling plants, the UKF has also been used for estimating parameters [28].

In this paper, the UKF estimates not only the temperature states but also the effective solar radiation reaching the metal tube. As stated in [29], pyrheliometers measure direct solar radiation locally. Current commercial plants cover great extensions of land [30]. Extrapolating the local measure from pyrheliometers to the rest of the field can lead to important errors, especially on transient days when passing clouds affect part of the field while the rest is not affected. Moreover, obtaining an estimation of the optical efficiency composed by multiple parameters such as mirror reflectivity, metal absorptance, shade factors etc, is a difficult task. The effectiveness of the proposed strategy is validated using a nonlinear distributed parameter model. Furthermore, two tests carried out at the real Fresnel solar field are also shown.

The control strategy proposed here is based on previous works such as [31]. However there are significant differences which are enumerated below:

1. The control strategy proposed in this paper, uses an incremental formulation of the MPC problem. This formulation avoids the need for using disturbance estimators to correct tracking reference errors in steady state. The formulation used here achieves offset-free tracking when step references are considered, and the system has no zero at $\mathrm{z}=1$, as shown in [32].

2. The solar plant is based on a Fresnel solar collector field which uses water as HTF, while the plant used in [31] is a solar trough using oil as HTF. The model of the plant and the controller itself are different.

3. In most previous works, the UKF+MPC control strategy has been tested using simulation models. In this paper, tests performed at the actual plant are provided. One of them is on a day when strong 


\begin{tabular}{ll}
\hline GS-GPC & Gain Scheduling Generalized Predictive \\
& Controller \\
HTF & Heat Transfer Fluid \\
ISE & Integral of square errors \\
MPC & Model Predictive Control \\
PCM & Phase Change Material \\
PDE & Partial Differential Equation \\
PID & Proportional+Integral+Derivative Controller \\
PV & Photovoltaics \\
UKF & Unscented Kalman Filter \\
\hline
\end{tabular}

Table 1: List of Abbreviations

radiation disturbances affect the solar field. This is one of the most extreme operating conditions in solar energy plants.

4. Although the tests were carried out using Matlab, the final control strategy will be programmed in a PLC installed at the plant for control purposes. For this reason, the computational burden and complexity of the proposed control strategy has to be as low as possible without deteriorating the performance substantially.

The paper is organized as follows: section 2 briefly describes the solar cooling plant. Section 3 presents the mathematical model of the Fresnel collector field used in this paper. Section 4 describes the MPC control strategy and the UKF nonlinear estimator. Section 5 shows the simulation results. Section 6 presents the tests performed at the actual plant. Finally, some concluding remarks are given.

\section{Brief plant description}

The solar cooling plant at the Escuela Superior de Ingenieros in Sevilla (Latitude $=37.4108972^{\circ}$, Longitude $=-6.0006621^{\circ}$ ), was constructed in 2008. Figure 1 shows the overall scheme of the solar cooling plant. The plant consists of three subsystems which are briefly described below.

Water absorption chiller: this is a double-effect cycle $\mathrm{LiBr}+$ absorption machine with $174 \mathrm{~kW}$ and a theoretical COP of 1.34, which transforms the thermal energy coming from the Fresnel solar field or the PCM storage tank, into cold water to be used by the ESI of Seville [10].

Solar Field: the solar field consists of a set of Fresnel solar collectors (see Figure 2) which concentrate solar radiation onto a $64 \mathrm{~m}$ metal tube through which pressurized water circulates.
PCM storage tank: the PCM storage is a 18 metre long shell-tube heat exchanger with a 1.31 metre diameter. It consists of a series of tubes containing a heat transfer fluid and PCM fills in the space between the tubes and the shell. In [33], further information about the storage tank can be found.

\section{Mathematical modeling of the Fresnel collector field}

In this section, the mathematical model of the solar collector field is presented. The equations governing the system dynamics are similar to those used in the case of the parabolic trough fields [34]. The difference depends on the computation of the geometrical efficiency and the shade factor.

There are two ways of modeling this kind of system: the concentrated parameter model and the distributed parameter model [35]. In this paper, the distributed parameter model is used for simulation purposes and for testing the performance of the proposed control strategy. The concentrated parameter model is used for obtaining a feedforward controller.

\subsection{Distributed parameter model}

As described in section 2, the Fresnel solar collector field consists of a set of Fresnel solar collectors which concentrate solar radiation onto a line where a $64 \mathrm{~m}$ long absorption tube is placed. The model dynamics is governed by the following system of partial differential equations (PDE) describing the energy balance [36]:

$$
\begin{gathered}
\rho_{m} C_{m} A_{m} \frac{\partial T_{m}(l, t)}{\partial t}=I K_{o p t} n o G_{a}-H_{l} G\left(T_{m}-T_{a}\right) \\
-L H_{t}\left(T_{m}-T_{f}\right) \\
\rho_{f} C_{f} A_{f} \frac{\partial T_{f}(l, t)}{\partial t}+\rho_{f} C_{f} q \frac{\partial T_{f}}{\partial l}=L H_{t}\left(T_{m}-T_{f}\right)
\end{gathered}
$$

where $m$ subindex refers to metal and $f$ subindex refers to a fluid. In Table 2, parameters and their units are shown.

The PDE system is solved by dividing the metal and fluid into $641 \mathrm{~m}$ long segments. The integration step is chosen to be 0.5 seconds and the integration technique is a Euler forward method. This method has been chosen for its simplicity, although there are more precise methods such as the runge-kutta integration algorithm.

One of the problems of the Euler forward method is that if the integration step is not small enough, numerical instabilities may appear [37]. In the case of solar 


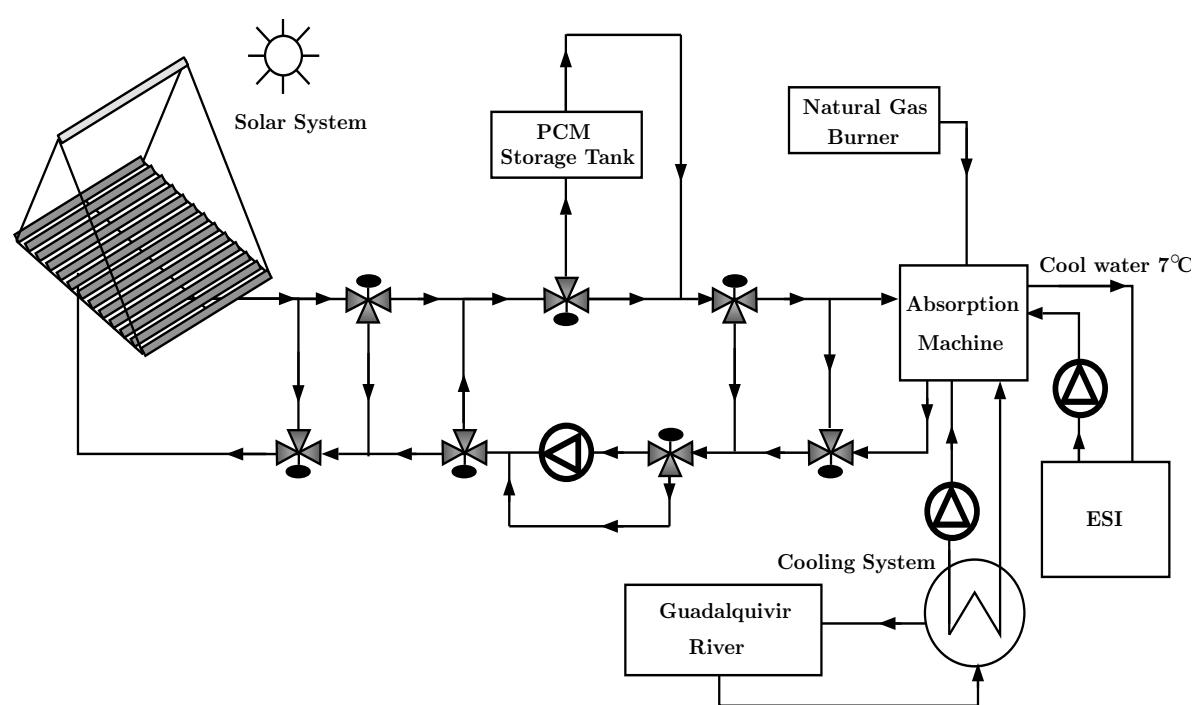

Figure 1: Plant general scheme

\begin{tabular}{|c|l|r|}
\hline Symbol & description & Units \\
\hline$t$ & Time & $s$ \\
$l$ & Space & $m$ \\
$\rho$ & Density & $\mathrm{kgm}^{-3}$ \\
$C$ & Specific heat capacity & $\mathrm{JK}^{-1} \mathrm{~kg}^{-1}$ \\
$A$ & Cross sectional area & $\mathrm{m}^{2}$ \\
$T(l, t)$ & Temperature & $\mathrm{K},{ }^{\circ} \mathrm{C}$ \\
$q(t)$ & Water flow rate & $\mathrm{m}^{3} \mathrm{~s}^{-1}$ \\
$I(t)$ & Direct Solar Radiation & $W m^{-2}$ \\
$n o$ & geometric efficiency & $\mathrm{Unitless}$ \\
$K_{o p t}$ & Optical efficiency & $\mathrm{Unitless}$ \\
$G_{a}$ & Collector aperture & $\mathrm{m}$ \\
$T_{a}(t)$ & Ambient temperature & $\mathrm{K},{ }^{\circ} \mathrm{C}$ \\
$H_{l}$ & Global coefficient of & $\mathrm{Wm}^{-2}{ }^{\circ} \mathrm{C}^{-1}$ \\
& thermal loss & \\
$H_{t}$ & Coefficient of heat trans- & $W m^{-2}{ }^{\circ} \mathrm{C}^{-1}$ \\
& mission metal-fluid & \\
$L$ & wetted perimeter & $m$ \\
$S$ & Total reflective surface & $m^{2}$ \\
$C_{t h}$ & Thermal capacity of the & $J / K$ \\
& solar field & \\
$P c_{p}$ & Parameter of solar field & $J_{T} m^{-3} K^{-1}$ \\
$T$ & average Temperature of & ${ }^{\circ} \mathrm{C}, \mathrm{K}$ \\
& the solar field & \\
\hline & &
\end{tabular}

Table 2: Parameter description

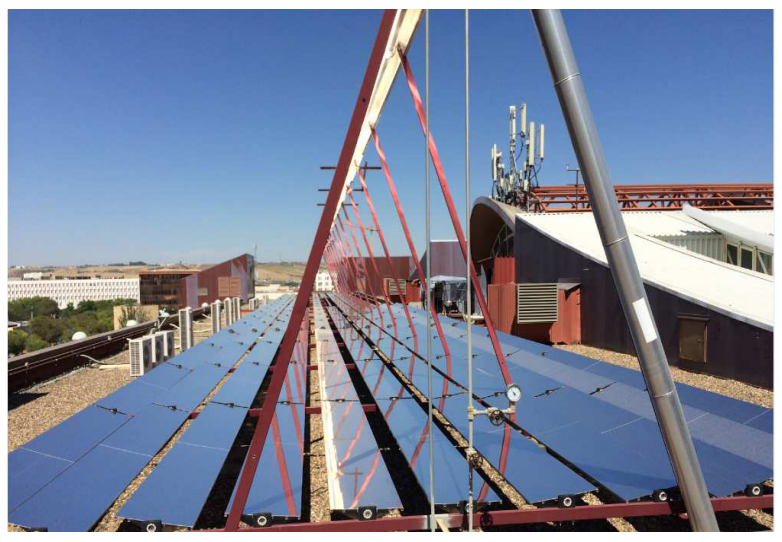

Figure 2: Fresnel collector field

energy systems, the most abrupt changes are produced when transients in solar radiation appear and produce abrupt changes in the temperatures. It has been found by test and error that if the integration step is chosen higher than 1.5 seconds, these numerical instabilities appear.

The computation of geometric efficiency, which takes into account the effect of the cosine of the incidence angle of the solar beam and the shade factor, involves complex trigonometric formulas. These formulas are explained in [38].

The density, specific heat and heat transmission coefficients have been obtained as polynomial functions of the segment temperature and water flow using thermodynamical data of pressurized water. The thermal loss coefficient has been obtained using real data from the 
Fresnel solar field. These expressions are valid from $0{ }^{\circ} \mathrm{C}$ to $250{ }^{\circ} \mathrm{C}$. This is sufficient for the model used here, because the solar cooling plant operating range is between $0{ }^{\circ} \mathrm{C}$ and $190{ }^{\circ} \mathrm{C}$. At $190{ }^{\circ} \mathrm{C}$, the solar field is defocused and the plant is shut down to prevent any possible damage to the equipment. The expressions are as follows:

$$
\begin{gathered}
\rho_{f}=-0.0025 T_{f}^{2}-0.203 T_{f}+1003.91 \\
C_{f}=5.16 e-7 T_{f}^{4}-1.56 e-4 T_{f}^{3}+0.0277 T_{f}^{2} \\
-1.627 T_{f}+4207.403 \\
H_{v}=1.34 e-4 T_{f}^{4}-7.78 e-2 T_{f}^{3}+18.73 T_{f}^{2} \\
-2.57 e 3 T_{f}+4.11 e 5 \\
H_{t}=H_{v} q^{0.8}
\end{gathered}
$$

The thermal loss coefficient can be calculated using equation (5):

$$
H_{l}=(0.00122)\left(T_{m}-T_{a}\right)+0.001763
$$

Figure 3 shows a comparison between the model and the real outlet temperature from the solar field. As can be seen, the model dynamics is very similar to the real one.
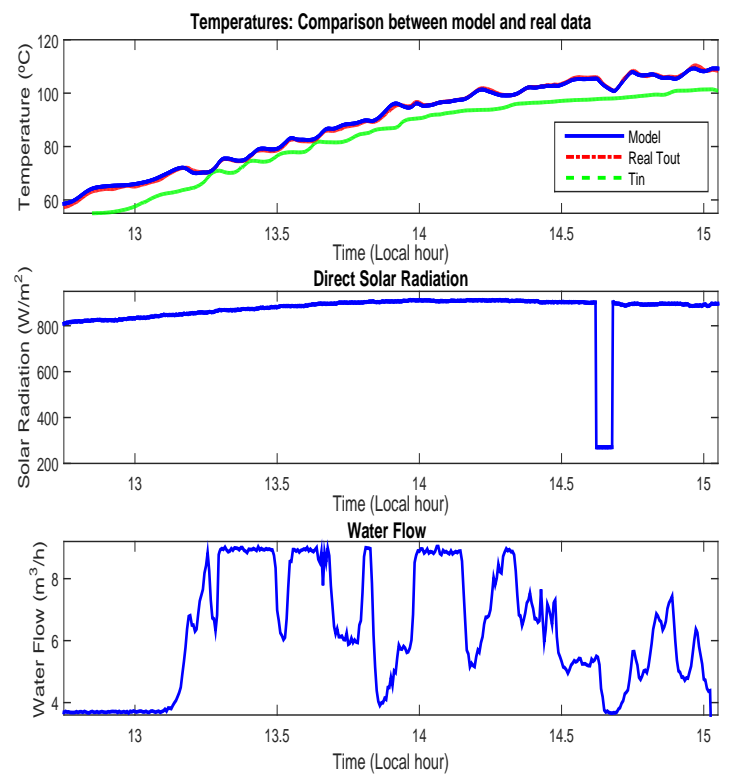

Figure 3: Solar field evolution Model vs Real: 31/07/2017

\begin{tabular}{|c|r|}
\hline Number of segments & Error $\left({ }^{\circ} \mathrm{C}\right)$ \\
\hline 64 & 1.45 \\
32 & 1.57 \\
16 & 1.7 \\
8 & 1.84 \\
4 & 1.96 \\
2 & 2.46 \\
1 & 2.83 \\
\hline
\end{tabular}

Table 3: Maximum Error between the model output and real temperature

\subsection{Concentrated parameter model}

The concentrated parameter model provides a lumped parameter description of the whole field. The variation in the internal energy of the fluid can be described by the equation [38]:

$C_{t h} \frac{d T_{\text {out }}}{d t}=K_{\text {opt }} n o S I-q P c_{p}\left(T_{\text {out }}-T_{\text {in }}\right)-H_{l}\left(\bar{T}-T_{a}\right)$

The parameters of the equation are shown in Table 2. The total value of the reflective surface is $352 \mathrm{~m}^{2}$.

\section{Model Predictive Control Strategy}

In this section, the proposed model predictive control strategy is presented. The linear model used in the MPC control strategy is a linearization of the nonlinear distributed parameter model (equations (1)). The tube is divided into 4 segments for the metal and fluid respectively, instead of the 64 segments used in the distributed parameter model. This simplification reduces the computational burden of the control strategy and the size of the tuning matrices of the unscented Kalman filter estimator [24]. This fact means that, since the number of the tuning parameters is smaller, the control strategy can be tuned more easily. The main drawback is the precision loss. Since the final control strategy is aimed at being installed on a PLC, reducing the computational burden becomes an important issue.

In order to choose the above-mentioned number of segments, a study has been carried out comparing the maximum error between the distributed parameter model and the actual plant temperature. The numerical results are shown in table 3 . As can be seen, the lower the number of segments, the higher the error expected. Moreover, when the number of segments is smaller than 4 , the error grows faster.

Since only the inlet and outlet temperature of the fluid are available, the intermediate segment temperatures and the metal segment temperature are estimated 
by means of a UKF. One of the advantages of using a $\mathrm{UKF}$ as a state estimator instead of other simpler approaches such as the Luenberger observer [39] is that the UKF uses the full nonlinear model without simplifications to obtain the estimation of the state and parameters. The problem is that, although results concerning the stability of nonlinear estimators have been obtained, as shown in [40], to mathematically prove the stability of the MPC+UKF set is still a challenge and an open problem, especially for PDE systems of the Fresnel collector field. In this paper, the UKF estimates the effective solar radiation reaching the metal tube, namely, product $I K_{\text {opt }}$ no.

Firstly, the MPC algorithm is introduced. Secondly, the procedure for obtaining the linear matrices is shown. Then, the UKF estimator is described and the incremental formulation of the state-space MPC is presented. This formulation avoids the necessity of a disturbance estimator to achieve offset-free reference tracking. Lastly, the final control scheme is shown and explained.

\subsection{Control Objectives in solar energy plants}

In solar thermal plants, the solar field heats up a heat transfer fluid. This fluid can be used for producing electricity in a turbine, or in an absorption machine in a solar cooling plant to deliver air conditioning as is the case here.

The control objective in a solar energy plant is to regulate the outlet temperature around a desired set-point. This set-point can be computed in order to satisfy optimal production [41], or any other criteria [17]. To accomplish this task the manipulated variable is the HTF flow. The fulfillment of this objective is not an easy task due to the complex dynamics and multiple disturbances which affect the solar field. The transport-delay depends strongly on the control signal (HTF flow) [42].

\section{2. $M P C$ control problem}

An MPC control strategy consists of the following steps [43, 44]: firstly, it uses a model to predict the process evolution depending on a given control sequence, then it computes the control sequence by minimizing an objective function. Only the first element of the control sequence is applied to the system (receding horizon strategy).

The difference in various MPC strategies is mainly related to the model used to predict the system evolution. The use of linear models and quadratic cost functions gives rise to a quadratic programming problem. If the model used in the MPC strategy is nonlinear, the resulting optimization problem is computationally harder to solve and attaining the global optimum is not, in general, ensured [45].

In this paper, the model used to predict the future evolution of the system is a linear state-space model and the cost function is considered to be quadratic.

In general, the mathematical expression of the MPC problem can be posed as follows:

$$
\begin{aligned}
\min _{\Delta u} J=\sum_{t=1}^{N_{p}}\left(y_{k+t \mid k}-y_{k+t}^{r e f}\right)^{\top}\left(y_{k+t \mid k}-y_{k+t}^{r e f}\right) \\
+\lambda \sum_{t=0}^{N_{c}-1} \Delta u_{k+t \mid k}^{\top} \Delta u_{k+t \mid k}
\end{aligned}
$$

s.t.

$$
\begin{aligned}
y_{k+t \mid k} & =f\left(\Delta u, y_{k+t-1}, y_{k+t-2}, \ldots\right) \\
u_{k+t \mid k} & =u_{k+t-1 \mid k}+\Delta u_{k+t \mid k} \\
u_{\min } & \leq u_{k+t \mid k} \leq u_{\max } \\
t & =0, \ldots, N_{p}-1
\end{aligned}
$$

where $N_{p}$ and $N_{c}$ stand for the prediction and the control horizons respectively. The parameter $\lambda$ penalizes the control effort. Then $u_{k} \equiv u_{k \mid k}$ is applied to the system. In this case, only constraints in the amplitude of the water flow have been considered.

\subsection{Obtaining the linear Matrices}

In this subsection, the procedure for obtaining the linear matrices is presented. The linear model of the PDE system (1) consists of a set of matrices depending on inputs and system states. Let $x$ be the state vector formed by the temperatures of the 4 metal and fluid segments, $T_{i n}$ the inlet temperature, $q$ the water flow , $I_{\text {eff }}=I K_{o p t} n_{o}$ the effective solar radiation, and $T_{a}$ the ambient temperature. $\Delta x$ is the length of the segments into which the tube is divided (in this case $416 \mathrm{~m}$ segments).

The linear model in continuous time is computed using (7):

$$
\begin{gathered}
\dot{x}_{t}=A x_{t}+B u_{t}+B_{d} d_{t} \\
y_{t}=C x_{t} \\
u_{t}=q \quad d_{t}=\left[\begin{array}{lll}
T_{\text {in }} & I_{\text {eff }} & T_{a}
\end{array}\right]^{\top}
\end{gathered}
$$


The linear matrices are computed as follows:

$$
\begin{aligned}
& P_{0}=\frac{-H_{l} G_{a}-L H_{t}}{\rho_{m} C_{m} A_{m}} \quad P_{1}=\frac{L H_{t}}{\rho_{m} C_{m} A_{m}} \\
& P_{2}=\frac{L H_{t}}{\rho_{f} C_{f} A_{f}} \quad P_{3}=\frac{q}{A_{f} \Delta l} \\
& P_{4}=-P_{2}-P_{3} \\
& A=\left(\begin{array}{cccccccc}
P_{0} & 0 & 0 & 0 & P_{1} & 0 & 0 & 0 \\
0 & P_{0} & 0 & 0 & 0 & P_{1} & 0 & 0 \\
\cdots & \cdots & \cdots & \ldots & \ldots & \cdots & \ldots & \ldots \\
0 & 0 & 0 & P_{0} & 0 & 0 & 0 & P_{1} \\
P_{2} & 0 & 0 & 0 & P_{3} & 0 & 0 & 0 \\
0 & P_{2} & 0 & 0 & P_{4} & P_{3} & 0 & 0 \\
\ldots & \ldots & \ldots & \ldots & \ldots & \ldots & \ldots & \ldots \\
0 & 0 & 0 & P_{2} & 0 & 0 & P_{4} & P_{3}
\end{array}\right)
\end{aligned}
$$

where the first 4 states correspond to the metal temperatures and the last 4 correspond to the fluid temperatures. The value of the control signal $q$ in matrix $A$ is the value around which the nonlinear model is linearized.

$$
\begin{aligned}
& B=\left[\begin{array}{llll}
0_{1 x 4} & \frac{1}{A_{f} \Delta x} & \cdots & \frac{1}{A_{f} \Delta l}
\end{array}\right]^{\top} \\
& B_{\text {Tin }}=\left[\begin{array}{lll}
0_{1 x 4} & \frac{q}{A_{f} \Delta x} & 0_{1 x 3}
\end{array}\right]^{\top} \\
& B_{\text {Ieff }}=\left[\begin{array}{ll}
1_{1 x 4} \cdot \frac{G_{a}}{\rho_{m} C_{m} A_{m}} & 0_{1 x 4}
\end{array}\right]^{\top} \\
& B_{T a}=\left[\begin{array}{llll}
\frac{H_{l} G}{\rho_{m} C_{m} A_{m}} & \cdots & \frac{H_{l} G_{a}}{\rho_{m} C_{m} A_{m}} & 0_{4 x 1}
\end{array}\right]^{\top} \\
& B_{d}=\left[\begin{array}{lll}
B_{\text {Tin }} & B_{\text {Ieff }} & B_{T a}
\end{array}\right]^{\top} \\
& C=\left[\begin{array}{llllllll}
0 & 0 & 0 & 0 & 0 & 0 & 0 & 1
\end{array}\right]
\end{aligned}
$$

Notice that the $A$ and $B_{T a}$ matrices depend on the system states, the water flow and the system parameters; $B_{\text {Tin }}$ is a function of the water flow $u$.

It is worth pointing out that only $\rho_{m}, C_{m}, A_{f}, A_{m}$ and $G$ are constants, whereas each parameter $H_{l}, p_{f}, C_{f}$ and $H_{t}$ depends on the temperature. The linear matrices are discretized using a sampling time of $20 \mathrm{~s}$. The sampling time has been chosen taking into account the typical time constants of the plant in closed loop. From now on we will refer to the discrete-time matrices keeping the notation $A, B$ and $B_{d}$. The discretization method chosen is a zero order hold method which assumes the control inputs are piecewise constant over the sampling period.

\subsection{Nonlinear state estimator: the unscented Kalman filter}

In this subsection the unscented Kalman filter (UKF) is described. For the model predictive control strategy, the temperature of metal and fluid segments and the effective solar radiation are needed. The temperature profiles and the estimation of effective solar radiation are used in the model predictive controller to obtain the prediction of the outlet temperature along the prediction horizon (see section 4.2).

In this plant, only the inlet and outlet temperatures are measurable, so the intermediate fluid segment temperature, the metal segment temperatures and the effective solar radiation have to be estimated. The nonlinear model used for the UKF is a simplified version of the one described by equations (1). The tube is divided into 4 segments instead of the 64 used in the full nonlinear model. This simplification is carried out in order to reduce the computational burden and the complexity of the control strategy [31].

The Kalman filter is a widely used tool for state estimation in linear systems [46]. The Kalman filter has been extended to nonlinear state estimation through algorithms such as the extended Kalman filter (EFK) or the unscented Kalman filter (UKF) [24].

The UKF is based on the unscented transformation, which represents a method for calculating the mean and covariance of a random variable that undergoes a nonlinear transformation [47, 48]. Since the appearance of the UKF algorithm, several improvements and variations have been developed $[49,50]$. In [51], an improved unscented transformation by incorporating the random parameters into the state vector in order to enlarge the number of sigma points is proposed. For more details about the UKF implementation, the reader is referred to [24].

Another important point to be addressed is that the changes in solar radiation can be abrupt and very fast. Since adequate solar field sampling time for control purposes is around 20 or 30 seconds, this may be too long for the UKF to capture the dynamics of radiation fast enough. In this paper the sampling time for control purposes is chosen to be $20 \mathrm{~s}$ and for the UKF, 10 seconds.

As far as the evolution of the effective solar radiation within the sampling time is concerned, several models for predicting solar radiation evolution have been proposed in literature $[52,53]$. The models provide only an estimation (nowcasting) of the future evolution. These models depend on multiple parameters such as the sunshine stability number and cloud transmittance which are not easy to know a priori. An estimation of these 
parameters would be necessary at the cost of increasing the model complexity. The approach used here is to consider that the effective solar radiation is constant along the sampling time. This is reasonable because the sampling time is small.

The Fresnel solar collector field has slow dynamics with a time constant of minutes. It was found that reducing the sampling time of the UKF did not produce any noticeable improvement in the estimation, because the evolution of the temperature is not significant for such a small sampling time. The minimum sampling time for the UKF would be 5 seconds because it is the minimum time to ensure correct communication between the PC where the controller is running and the data acquisition system. Figure 4 shows the evolution of the error in the effective solar radiation for different sampling times. As can be seen the error decreases with respect to the sampling time but the difference between $5 \mathrm{~s}$ and 10 seconds is quite small.

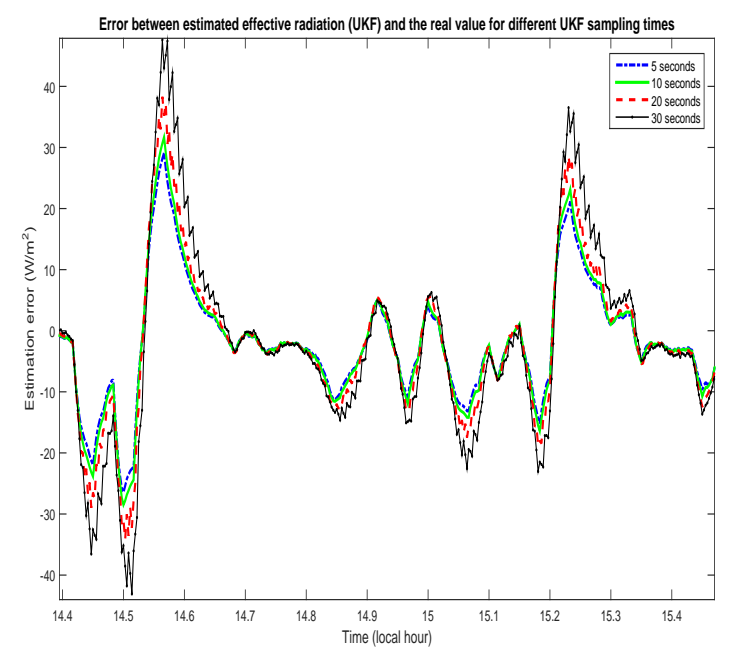

Figure 4: Effective solar radiation error for different UKF sampling times

\subsection{Incremental formulation of the state-space $M P C$}

In this subsection, the incremental formulation of the state-space formulation is presented.

The main problem when using state-space models in model predictive control strategy is that steady-state errors may appear due to model-plant mismatches. This problem is usually addressed by using a disturbance estimator $[54,55]$. This approach has the drawback that additional dynamics is added to the control system and more parameters have to be tuned properly. Thus, the complexity of the overall control scheme increases.
In this paper, an incremental formulation is used [32]. This formulation has the advantage of avoiding the need of a disturbance estimator for offset-free reference tracking when step references are given. The procedure is fully described in [32].

Considering a linear state-space model with $n$ states, $m$ outputs, $r$ inputs and $l$ disturbance sources:

$$
\begin{gathered}
x_{k+1}=A x_{k}+B u_{k}+B_{d} d_{k} \\
y_{k}=C x_{k}
\end{gathered}
$$

The key, as shown in [32], is to use an incremental form of the state space formulation and augment the states to include the system output. The incremental formulation is described as follows:

$$
\Delta x_{k+1}=A \Delta x_{k}+B \Delta u_{k}+B d \Delta d_{k}
$$

$$
y_{k}=y_{k-1}+C \Delta x_{k}
$$

where $\Delta x_{k}=x_{k}-x_{k-1}$. Augmenting equations (20) and (21), the complete state-space model is posed as follows:

$$
\begin{gathered}
\overbrace{\left[\begin{array}{c}
\Delta x_{k+1} \\
y_{k}
\end{array}\right]}^{\tilde{x}_{k+1}}=\overbrace{\left[\begin{array}{cc}
A & 0_{n \times m} \\
C & I_{m \times m}
\end{array}\right]}^{\tilde{A}}+\overbrace{\left[\begin{array}{c}
\Delta x_{k} \\
y_{k-1}
\end{array}\right]}^{\tilde{x}_{k}}+\overbrace{\left[\begin{array}{c}
B \\
0_{m \times r}
\end{array}\right]}^{\tilde{B}} \Delta u_{k}+ \\
\overbrace{\left[\begin{array}{c}
B d \\
0_{l \times r}
\end{array}\right]}^{\tilde{B d}} \Delta d_{k} \\
y_{k}=\overbrace{\left[\begin{array}{cc}
\left.C I_{m \times m}\right] \\
\tilde{C}
\end{array}\left[\begin{array}{c}
\Delta x_{k} \\
y_{k-1}
\end{array}\right]\right.}^{\tilde{B}}
\end{gathered}
$$

The new system can be posed as follows:

$$
\begin{gathered}
\tilde{x}_{k+1}=\tilde{A} \tilde{x}_{k}+\tilde{B} \Delta u_{k}+\tilde{B d} \Delta d_{k} \\
y_{k}=\tilde{C} \tilde{x}_{k}
\end{gathered}
$$

Since the model used is linear, the predicted response of the system can be described by the sum of the forced response, a term which depends on the future control actions, and the free response which does not depend on the future control actions [43], as follows:

$$
y=G \Delta u+f
$$


Matrix $G$ can be obtained from the model matrices (equations (25) and (26)) and the free response can be computed as a matrix depending on the past values of the states, outputs and measured disturbances. Since it is difficult to know the future evolution of the disturbances, the approach used in this paper is to assume that they remain constant along the prediction horizon.

Although estimating the future evolution of the main disturbance sources affecting the solar field (in this case, the evolution of solar radiation and inlet temperature) would produce better disturbance rejection, precise models to estimate this evolution would be required to do this.

In the case of solar radiation, several models have been proposed to predict its evolution $[52,53]$. These models depend on multiple parameters which are difficult to estimate. Furthermore, although an estimation of the future evolution on a clear day is possible at the cost of a more complex control strategy, obtaining this estimation on a cloudy day is not an easy matter. An estimation of the position of the clouds and how they affect the solar field would be necessary, and this is a very difficult and open problem.

With regard to the inlet temperature of the solar field, to be able to estimate its evolution, a nonlinear model of the plant would be required in order to estimate the temperature evolution of all the subsystems and the pipe connecting these subsystems with the solar field along the prediction horizon. The resulting control strategy would be a nonlinear model predictive control strategy which is more complex to solve. Since the proposed control strategy is aimed at being installed on a PLC system, this approach has to be ruled out.

The free response can be calculated as follows [43]:

$$
f=F\left[\begin{array}{c}
\Delta \tilde{x}_{k} \\
y_{k-1}
\end{array}\right]+G_{I_{e f f}} \Delta I_{e f f}+G_{T_{i n}} \Delta T_{i n}+G_{T_{a}} \Delta T_{a}
$$

where matrix $\mathrm{F}$ can be obtained from the model, and matrices $G_{I_{e f f}}, G_{T_{a}}$ and $G_{T_{i n}}$ are the contribution of each variable to the future evolution of the linear system.

\subsection{Final control Scheme}

This subsection explains the final control scheme shown in Figure 5. It works as follows:

Each estimation sampling time (10 seconds), the unscented Kalman filter receives the variables from the solar field and environmental conditions: inlet and outlet temperatures, ambient temperature, solar time and the water flow applied in the previous instants. Taking into account this information, it estimates a fluid- metal temperature profile and the effective solar radiation. This estimation is transmitted to the control block which is computed every 20 seconds. The linear control block computes the linear matrices associated to the current operation point of the solar field and solves the linear MPC control problem obtaining a control signal, qpred. This signal is added to a feedforward compensation, $q f f$. This sum is the final control signal sent to the Fresnel solar field. The feedforward compensation is computed as follows:

$$
q f f=\frac{I_{e f f} S-H_{l}\left(\bar{T}-T_{a}\right)}{P c_{p}\left(T_{r e f}-T_{i n}\right)}
$$

Although the MPC control strategy adapts its model to the current operating conditions, the control problem is linear, that is, the control signal computed by the MPC is a variation around the operating point. In order to help the linear MPC algorithm, the feedforward provides a steady-state water flow for the desired temperature reference and the MPC controller is added to correct it. If the model were perfect the feedforward compensation would be sufficient to track the desired reference without errors.

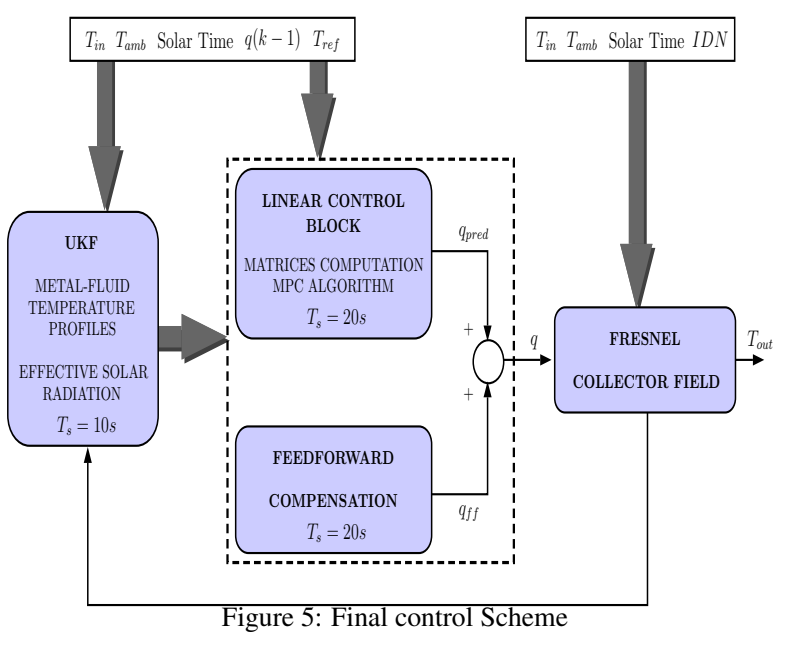

\section{Simulation results}

In this section, simulations testing the performance of the proposed control strategy are presented. The platform used to perform the simulations was an i3 with 4 GB of RAM. The software used is Matlab 2014 ®. The maximum computational time obtained for the overall control strategy was 0.7 seconds.

Firstly, a simulation showing the estimation of the solar radiation provided by the UKF estimator using 
data taken from the actual Fresnel solar collector field is performed. Then, two simulations are carried out comparing the proposed MPC strategy to a PID+series feedforward. The effective solar radiation used in the PID+series feedforward is the one measured, not the one estimated by the UKF. The simulations are performed using the nonlinear distributed parameter model. The tuning parameters for the MPC are $N_{c}=10, N_{y}=$ 14 and $\lambda=2 e 8$. The water flow is constrained to 3.6 and $10 \mathrm{~m}^{3} / \mathrm{h}$. These values were obtained in order to provide fast responses without producing great oscillations and brisk control actions.

The PID controller has the following expression:

$$
u_{\text {pid }}=0.1 e(k)+0.8 \frac{\Delta e(k))}{T_{s}}+6.29 e-3 \operatorname{Ierror}(k)
$$

where $I_{\text {error }}(k)$ is the value of the error integral at instant $k$ and $\Delta e(k)$ is the increment of the error computed as $e(k)-e(k-1) . T_{s}$ is the sampling time. The parameters of the PID were adjusted using data from different environmental conditions (clear and cloudy days). The initial design of the PID was for the medium water flow conditions. However, since the PID is a fixed parameter controller, when the plant evolves far from these conditions, the performance deteriorates [56]. Taking this initial design, the parameters were tuned to work properly (without great oscillations) throughout the entire range of operations by a test and error method.

The unscented Kalman filter has been tuned using a set of data taken from different operation days of the actual Fresnel collector field. The covariance matrices $Q$ and $R$ for the UKF [24], were tuned by a test and error method. Obtaining the $Q$ and $R$ matrices is one of the problems of using a Kalman filter, since they are not generally known and have to be estimated.

The covariance matrix of sensor $R$ was set to 0.01 . The actual value is not known, but the temperature sensor measurement is considered to have a small variance. Matrix $Q$ is the covariance of the states. In this paper, the size of the $Q$ matrix is $9 \times 9$ since the states to be estimated are the eight segment temperatures ( 4 metal and 4 fluid segments) and the effective solar radiation. The covariance value of the temperature states is considered to be low, that is, the estimation uncertainty is small and the parameter with a higher uncertainty is the effective solar radiation. The matrix has been chosen as a diagonal for simplicity.
The final $Q$ matrix obtained is as follows:

$$
Q=\left(\begin{array}{ccccccc}
1 e-2 & 0 & 0 & 0 & 0 & 0 & \ldots \\
0 & 1 e-2 & 0 & 0 & 0 & 0 & \ldots \\
0 & 0 & 1 e-2 & 0 & 0 & 0 & \ldots \\
\ldots & \ldots & \ldots & \ldots & \ldots & \ldots & \ldots \\
\ldots & 0 & 0 & 0 & 0 & 0 & 0.5
\end{array}\right)
$$

\subsection{UKF tuning}

Figure 6 shows a day when the Fresnel collector field was connected to the absorption chiller. The top part of the figure shows the evolution of the inlet and outlet temperatures. As shown, they present oscillatory behavior due to the return temperature of the absorption chiller. The bottom part of the figure depicts the water flow, which was about $12 \mathrm{~m}^{3} / \mathrm{h}$ and the solar radiation measured by the pyrheliometer and that estimated by the UKF. To obtain the measured effective solar radiation, the overall $K_{o p t}$ parameter is chosen from several studies to be 0.35 . As can be seen, the effective solar radiation estimated by the UKF approximately follows the measured effective solar radiation.
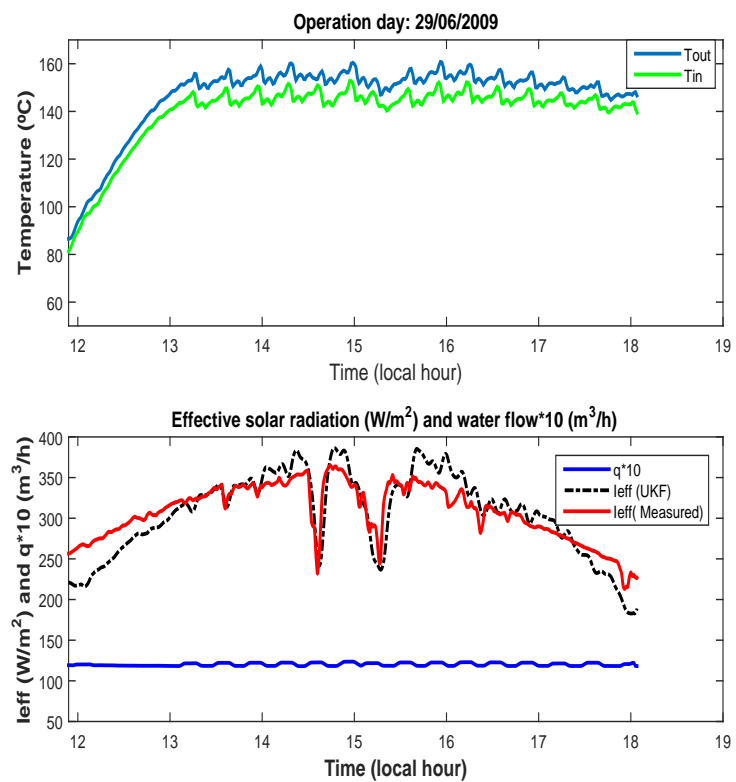

Figure 6: UKF tuning with real data

\subsection{Comparison with a fine-tuned PID}

For the simulations shown below, parameter $K_{o p t}$ is chosen to be 0.25 . This parameter was estimated by a 
set of data collected on several operational days in 2017. There are 4 inoperative rows out of 22 and some miscalibrated mirrors. For the sake of clarity, the effective solar radiation is scaled by multiplying by a factor of 4 , and the water flow is multiplied by 100 , in order to plot them in the same figure.

\subsubsection{Clear day at high temperature}

Figure 7 shows the first simulation which consists of a series of increasing temperature references on a clear day. This kind of situation is typical when the plant is stable at a nominal point, the absorption machine is operating and connected to the solar field. The objective is to change the set-point of the solar field according to the temperature needed by the absorption chiller.

As can be seen, the proposed control strategy performance maintains good tracking behavior throughout the simulation whereas the PID performance deteriorates at low water flow levels. As seen at the bottom of figure 7 , the estimated effective solar radiation is very close to the real one. This steady-state error may be produced by the fact that the model used to estimate it is a simplified version of the full distributed nonlinear model. Another point is that the MPC control strategy better rejects the inlet temperature disturbances due to its prediction capability.
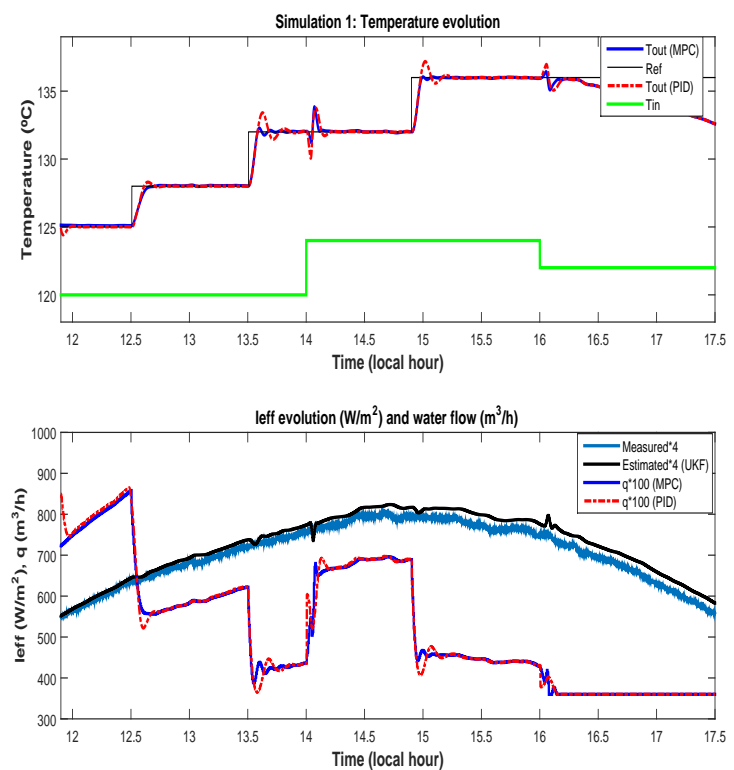

Figure 7: Simulation 1: clear day

Figure 8 shows the contribution of the feedforward and the MPC to the final control signal. As can be seen, the feedforward acts as a high gain signal and the MPC contributes as a small gain signal to track the desired set-point and remove the steady-state error. Since the model is not perfect, the feedforward compensation is not sufficient to remove the steady-state error. This is done by the MPC signal.
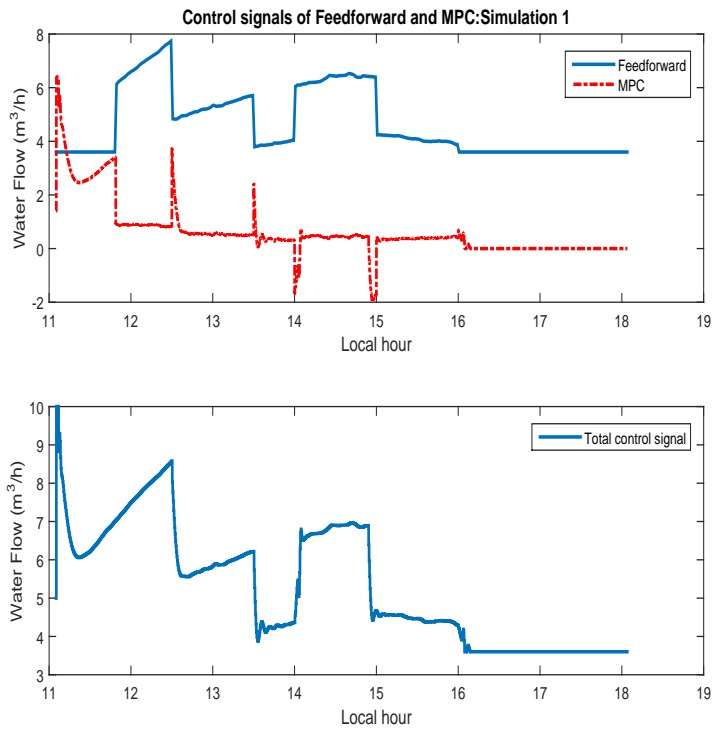

Figure 8: Simulation 1: Feedforward and MPC control signals

\subsubsection{Start-up stage: recirculation mode}

Figure 9 shows the simulation performed using real data of the Fresnel solar plant. On this day, the plant was working in recirculation mode, where the outlet temperature is recirculated through a long pipe and returns to the solar field. This situation is typical when the plant is at the start-up stage, when the objective is to raise the temperature of the solar field in order to reach a value high enough to feed the water chiller.

It can be observed that the MPC is generally faster and tracks the temperature references better than the PID controller. At $14.1 \mathrm{~h}$, the solar field was completely defocused, causing the effective solar radiation to fall to $0 \mathrm{~W} / \mathrm{m}^{2}$. The estimated effective solar radiation follows this drop in a smoother way. This is a drawback when using the estimated effective solar radiation: the UKF estimation evolves when the effect of the real effective solar radiation is observed in the outlet temperature. This fact produces a loss of anticipative action, partially compensated by the prediction capabilities of the MPC strategy. To make the UKF faster, a higher gain can be chosen but it may produce a more 
oscillatory behavior. One possible solution could be to use a fault tolerant algorithm that selects which measure to use: that provided by the pyrheliometer or the estimation provided by the UKF. In any case, as seen in simulation results, the MPC algorithm rejects the disturbances properly, achieving good reference tracking.
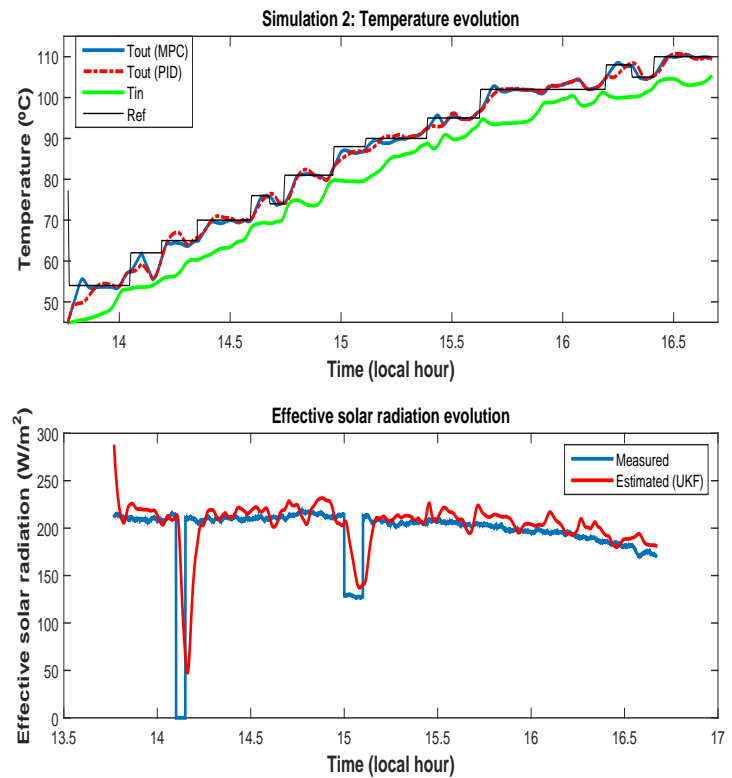

Figure 9: Simulation 2

Figure 10 shows the water flow signals of the MPC and PID.

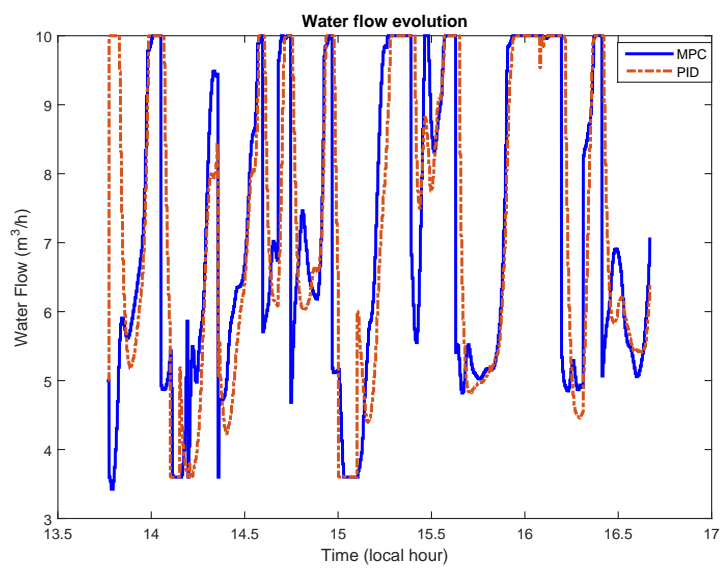

Figure 10: Simulation 2: water flow evolution

As in the first simulation, figure 11 shows the contribution of the feedforward controller and the MPC to the overall control signal. The conclusions obtained are similar to those obtained in the first simulation.
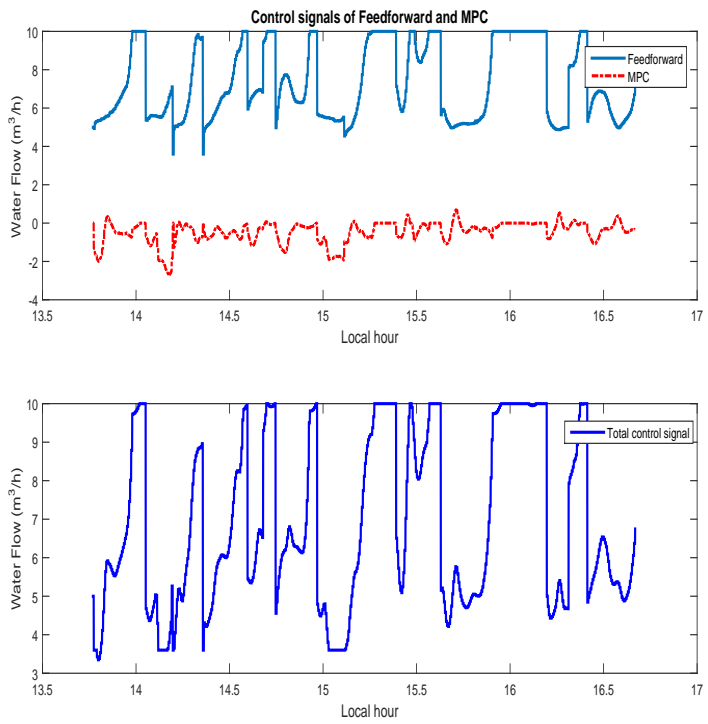

Figure 11: Simulation 2: Feedforward and MPC control signals

Figure 12 shows the metal-fluid temperature profiles estimated by the UKF algorithm. As can be seen, the estimation is very close to that obtained by the nonlinear distributed parameter model, with a maximum error of 0.5 .

\subsubsection{Performance comparison between using a paral- lel feedforward or not}

In this subsubsection, a performance comparison between using a parallel feedforward or not is carried out.

The MPC uses the measured disturbances and variables from the plant to predict the evolution of the outlet temperature. The model used to do this is linear. In consequence, the control signal computed by the MPC can be interpreted by a small gain signal to be added to a high gain signal. This high gain signal is the flow computed by the feedforward.

If the feedforward is not used, the MPC has worse performance, as shown in figure 13. The use of the feedforward helps by rejecting the disturbances. Better performance and a higher degree of robustness when controlling the actual plant are achieved [56].

An ISE (Integral of square error) performance index has been calculated for the two strategies. The result is: $I S E_{n o f f}=1420.6$ and $I S E_{f f}=920.6$. 

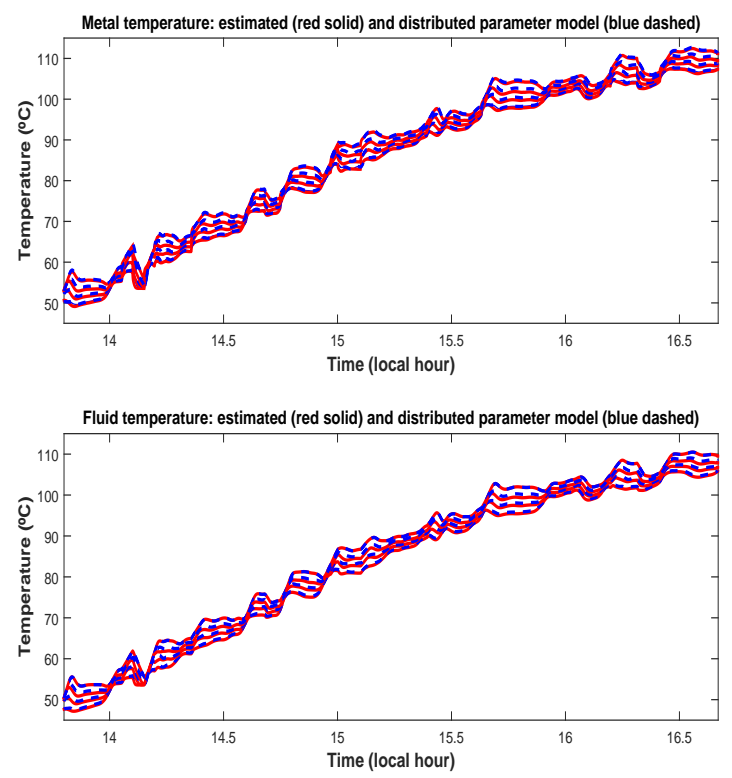

Figure 12: Simulation 2: Metal-fluid temperature profiles estimation
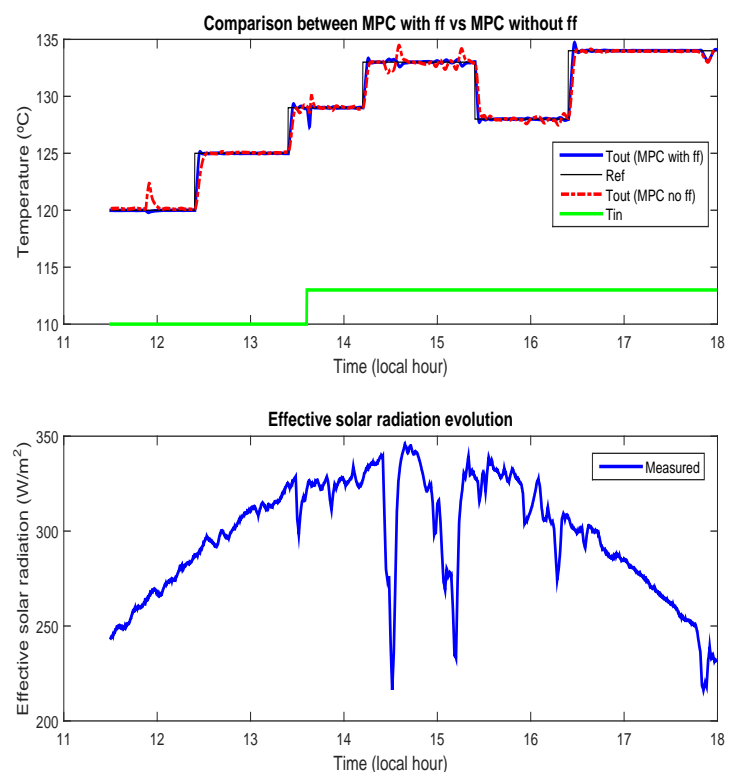

Figure 13: Simulation 3: Performance comparison between using ff vs no ff

\subsection{Comparison with Gain Scheduling GPC}

In this subsection, a performance comparison with a Gain scheduling GPC (GS-GPC) is carried out [57]. The GS-GPC control strategy has been tested at the actual plant with very good performance.

Basically the control strategy consists of a generalized model predictive control strategy which adapts the linear model (discrete transfer function) with respect to the flow level. The control strategy uses a series feedforward to reject the disturbances affecting the solar field. For a complete description of the control strategy see [23].

\subsubsection{Clear day at stable temperature}

On this day, shown in figure 14, the field is operating with a stable inlet temperature and the set-points for the outlet temperature are changed. As can be observed, both control strategies correctly track the temperature reference, performing well at all flow levels. Slightly faster responses are obtained with the MPC controller.

Some transients affect the plant and both control strategies reject the disturbance and track the temperature reference correctly. The effective solar radiation estimated by the UKF is very close to the measured one.
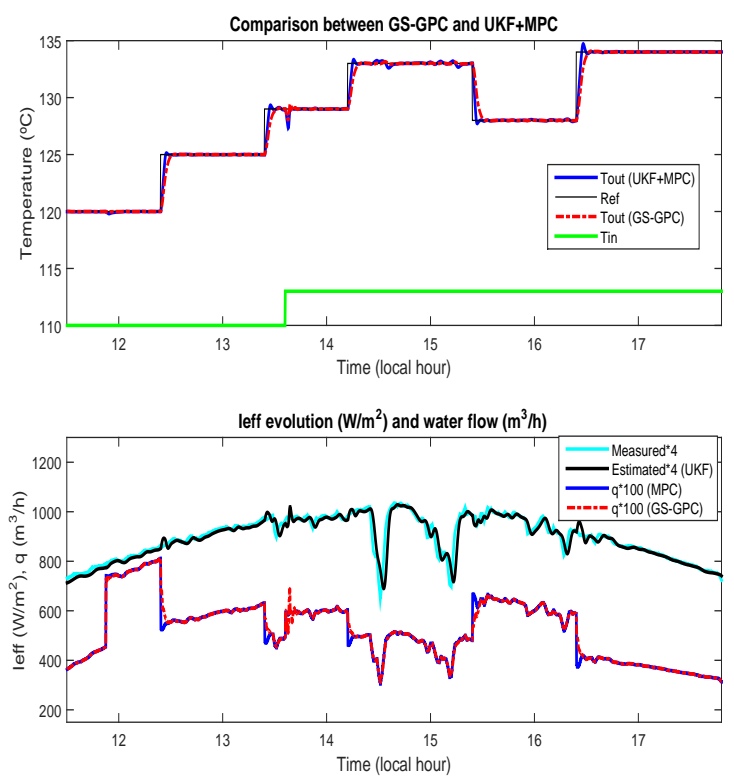

Figure 14: Simulation 4: Performance comparison between MPC and GS-GPC: tracking references 


\begin{tabular}{|c|c|c|}
\hline & MPC & GS-GPC \\
\hline Sim 1 & 941.1503 & $1.2619 \mathrm{e}+03$ \\
\hline Sim 2 & $3.6022 \mathrm{e}+03$ & $3.9478 \mathrm{e}+03$ \\
\hline
\end{tabular}

Table 4: ISE criterion for both simulations: MPC vs GS-GPC

\subsubsection{Recirculation mode}

This simulation is very similar to the second simulation of the PID case. The plant is working in recirculation mode where the outlet temperature returns to the inlet temperature after circulating through a pipe. In this mode, the plant is constantly affected by inlet temperature disturbances which hinder the set-point tracking.

In this case, the MPC achieves faster responses and better disturbance rejection. This can be observed in table 4, which shows the ISE performance criterion. In both cases, the MPC achieves better performance than the GS-GPC strategy.
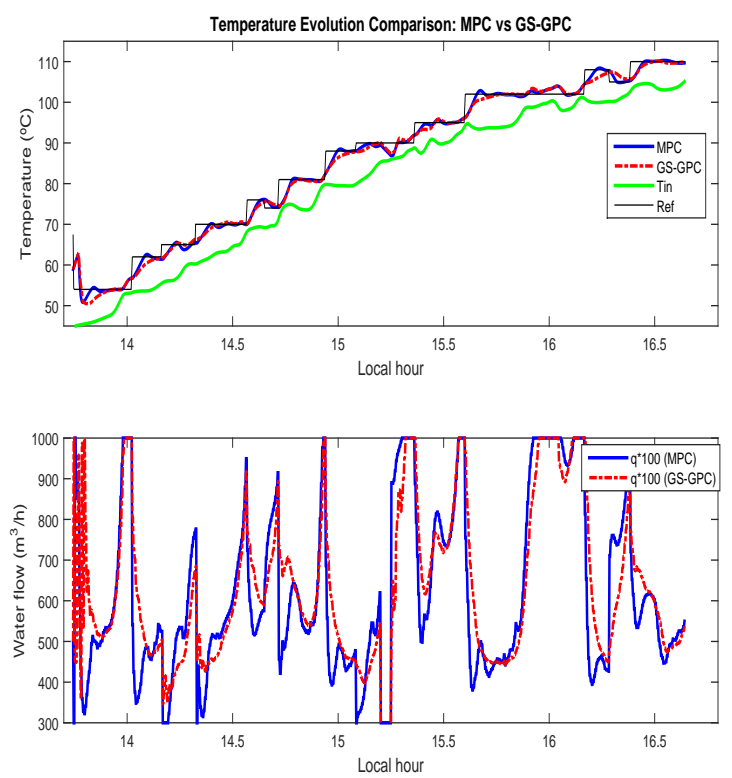

Figure 15: Simulation 5: Performance comparison between MPC and GS-GPC: tracking references in recirculation mode

\section{Real Tests}

In this section, two tests carried out at the actual Fresnel collector field are presented. In these tests the water flow is constrained to 3.7-9 $\mathrm{m}^{3} / \mathrm{h}$. The parameters of the MPC $N_{c}=10, N_{y}=14$ and $\lambda=4 e 8$. Parameter $\lambda$ is chosen higher than that used in simulations to obtain less aggressive control actions.
Both tests were carried out in recirculation mode. In this mode, the heated water is recirculated and returned to the solar field after passing through a long pipe. This kind of disturbance is difficult to deal with. If the controller is not properly tuned, oscillations are produced in the outlet temperature. These oscillations propagate to the input of the solar field, later producing more oscillations. Furthermore, the inlet temperature disturbance delay depends on the water flow. Taking anticipated actions to reject the inlet temperature disturbance is not an easy matter.

Figure 16 shows the test carried out on 27/10/2017. It consisted of a series of steps in the temperature reference. The MPC controller tracks the reference well, without being too aggressive with the control actions. At $12.5 \mathrm{~h}$, communication was cut off and the temperature reference was the default value of $120^{\circ} \mathrm{C}$. When communication was recovered shortly after, the test was resumed. The controller tracked all the temperature references correctly.
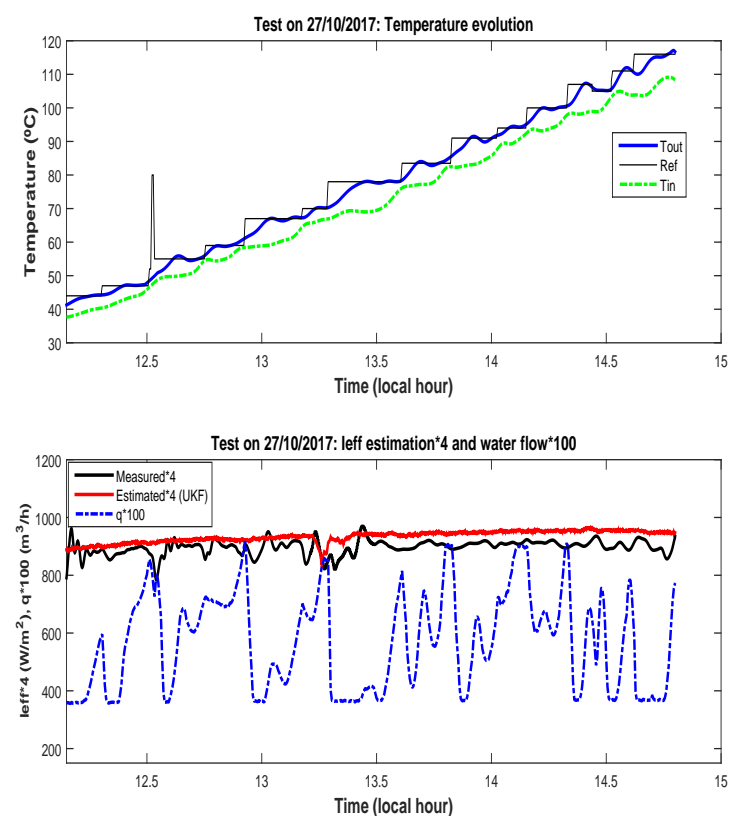

Figure 16: Test carried out on 27/10/2017

The bottom part of figure 16 shows the water flow and effective solar radiation. As seen, the effective solar radiation estimated by the UKF is slightly lower than the measured one, probably because some miscalibrated mirrors produced lesser optical efficiency. However, the dynamics estimation is similar to that measured, although some oscillations can be observed, produced by 
the constant changes in outlet temperature, inlet temperature and water flow.

Figure 17 shows a test carried out on 13/10/2017. It was a cloudy day with strong changes in solar radiation. The environmental conditions did not allow the temperature to rise much, but the test showed that the controller could track the temperature references even under such adverse conditions. For example, from 15.2 h onwards, the controller could not reach the desired set-point because strong solar radiation disturbances were affecting the solar field. The controller went to minimum water flow but, under these conditions, the reference was unreachable because there was not enough solar energy to heat the water up to the set-point . From $15.6 \mathrm{~h}$ to $15.75 \mathrm{~h}$, the controller reached the desired reference and rejected the disturbances correctly. From $15.75 \mathrm{~h}$ onwards, the solar radiation levels were very low and the operation finished.
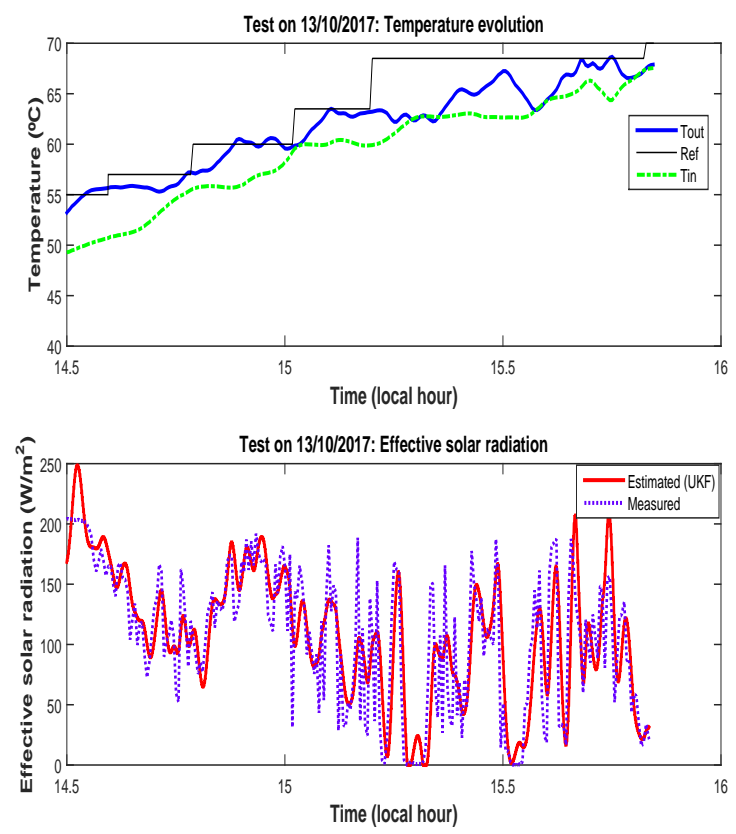

Figure 17: Test carried out on 13/10/2017

The effective solar radiation estimated by the UKF is a smoother version than the one measured. This can be an advantage on this kind of day, because the measured solar radiation is used and very abrupt changes in the water flow to reject the disturbance may appear [56].

Finally, figure 18 shows the control signal. As can be seen, the changes in the control signal are not aggressive in spite of the strong changes in solar radiation.

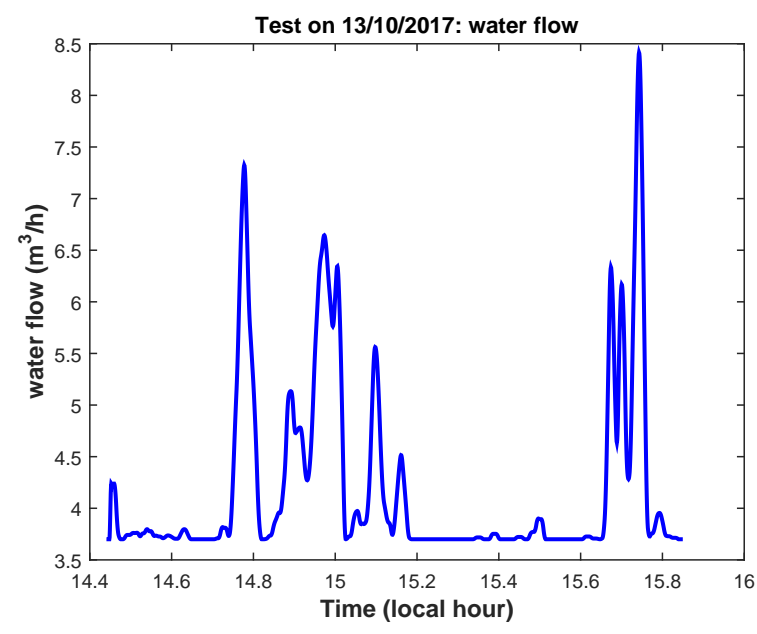

Figure 18: Test carried out on 13/10/2017: Water flow signal

\section{Concluding Remarks}

In this paper, an adaptative model predictive control strategy was designed for the Fresnel collector field located at the Escuela Superior de Ingenieros de Sevilla. The controller uses an unscented Kalman filter as state estimator which estimates metal-fluid temperature profiles. The UKF also estimates the effective solar radiation reaching the tube.

Simulation results were provided comparing the proposed strategy to a PID+feedforward series controller, showing better performance. A comparison to a more sophisticated control strategy, a GS-GPC strategy, which has been tested showing very good performance at the actual plant. The proposed strategy outperforms these two control strategies, showing good tracking properties throughout the entire range of operation.

Furthermore, two real tests carried out at the actual plant are presented. In both tests, a wide range of operating conditions are covered: temperature set-point tracking, disturbance rejection, and operating when strong radiation disturbances are affecting the plant.

The proposed controller achieves adequate set-point tracking in spite of strong disturbances. The final outcome can be considered satisfactory.

\section{Acknowledgements}

The authors would like to acknowledge the European Research Council, the Spanish Ministry of Economy, Industry and Competitiveness and the UE ERDF for funding the work under the Advanced Grant OCONTSOLAR (Project ID: 789051), Control Predictivo 
de Microrredes Reconfigurables con Almacenamiento Híbrido y Móvil (DPI2016-78338-R) and ENERPRO (DPI2014-56364-C2-1-R).

\section{References}

[1] D. Y. Goswami, F. Kreith, J. F. Kreider, Principles of Solar Engineering, 2nd Edition, Taylor\&Francis, 2000.

[2] E. F. Camacho, M. Berenguel, Control of solar energy systems, in: 8th IFAC Symposium on Advanced Control of Chemical Processes, 2012, pp. 848-855.

[3] Y. Chu, Review and comparison of different solar energy technologies, Tech. rep., Global Energy Network Institute (2011).

[4] Solana Generating Station (Sep. 2018). [link].

URL https://solarpaces.nrel.gov/ solana-generating-station

[5] Mojave Solar Project (Sep. 2018). [link].

URL https://solarpaces.nrel.gov/ mojave-solar-project

[6] Yumen 50MW Thermal Oil Trough CSP project (2019). [link]. URL https://solarpaces.nrel.gov/ yumen-50mw-thermal-oil-trough-csp-project

[7] Solar Paces, Concentrating solar power projects by project name (2019).

URL https: //solarpaces.nrel.gov/projects

[8] D. Kima, C. Infante-Ferreira, Solar refrigeration options a state-of-the-art review, International Journal of Refrigeration 31 (2008) 3-15.

[9] D. N. Nkwetta, J. D. Sandercock, A state-of-the-art review of solar air-conditioning systems, Renewable and Sustainable Energy Reviews 60 (2016) 1351-1366.

[10] P. Bermejo, F. J. Pino, F. Rosa, Solar absorption cooling plant in seville, Solar Energy 84 (2010) 1503-1512.

[11] C. M. Cirre, M. Berenguel, L. Valenzuela, R. Klempous, Reference governor optimization and control of a distributed solar collector field., European Journal of Operational Research 193 (2009) 709-717.

[12] F. R. Rubio, E. F. Camacho, M. Berenguel, Control de campos de colectores solares, RIAI Vol 3, No.4 (2006) 26-45.

[13] E. F. Camacho, M. Berenguel, F. Rubio, D. Martínez., Control of Solar Energy Systems, Springer-Verlag, 2012.

[14] J. M. Lemos, R. Neves-Silva, J. M. Igreja, Adaptive Control of Solar Energy Collector Systems, Springer-Verlag, 2014.

[15] G. Pin, M. Falchetta, G. Fenu, Adaptative time-warped control of molten salt distributed collector solar fields, Control Engineering Practice 16 (2007) 813-823.

[16] G. A. Andrade, D. J. Pagano, J. D. Álvarez, M. Berenguel, A practical nmpc with robustness of stability applied to distributed solar power plants, Solar Energy 92 (2013) 106-122.

[17] B. Khoukhi, M. Tadjine, M. S. Boucherit, Nonlinear continuoustime generalized predictive control of solar power plant, Int. J. Simul. Multisci. Des. Optim. A3 (6) (2015) 1-12. doi:10.1051/smdo/2015003.

[18] A. Alsharkawi, J. A. Rossiter, Towards an improved gain scheduling predictive control strategy for a solar thermal power plant, IET Control Theory \& Applications 11(12) (2017) 19381947.

[19] K. Witheephanich., J. M. Escano, C. Bordóns, Control strategies of a solar cooling plant with fresnel collector: a case study, in: International Electrical Engineering Congress IEEECON, Chonburi (Thailand), 2014.

[20] L. Xian-Juan, D. Hai-Ying, Application research of sliding mode predictive control based on feedforward compensation in solar thermal power generation heat collecting system, International Journal of Hybrid Information Technology 9(3) (2016) 211-220.

[21] A. Aurousseau, V. Vuillerme, J.-J. Bezian, Control systems for direct steam generation in linear concentrating solar power plants a review, Renewable and sustainable Energy Reviews 56 (2016) 611-630.

[22] M. M. Mokhtar, Control of solar thermal linear fresnel collector plants in single phase and direct steam generation modes (2018).

[23] A. J. Gallego, G. M. Merello, M. Berenguel., E. F.Camacho, Gain-scheduling model predictive control of a fresnel collector field, Control 82 (2019) 1-13.

[24] S. Haykin, Kalman Filtering and Neural Networks, A WileyInterscience Publication, 2001

[25] G. Pin, M. Falchetta, G. Fenu, Modeling and control of concentrating solar power systems: a discrete-time adaptative scheme for temperature control in molten-salt solar collector-fields, In Solar Collectors: Energy Conservation, Design and Applications Series: Renewable Energy: Research, Development and Policies. Nova Publishers (2009) 15-39.

[26] P. Gil, J. Henriques, A. Cardoso, P. Carvalho, A. Dourado, Affine neural network-based predictive control applied to a distributed solar collector field, IEEE TRANSACTIONS ON CONTROL SYSTEMS TECHNOLOGY, 22(2) (2014) 585596.

[27] M. Karamali, M. Khodabandeh, A distributed solar collector field temperature profile control and estimation using inlet oil temperature and radiation estimates based on iterative extended kalman filter, Renewable Energy 101 (2017) 144-155.

[28] T. Ferhatbegovic, G. Zucker, P. Palensky, An unscented kalman filter approach for the plant-model mismatch reduction in hvac system model based control, in: IECON 2012 - 38th Annual Conference on IEEE Industrial Electronics Society, 2012. doi:10.1109/IECON.2012.6388685.

[29] A. J. Gallego, E. F. Camacho, Estimation of effective solar radiation in a parabolic trough field, Solar Energy 86 (2012) 35123518.

[30] A. Yield (2017). [link]. URL http: / / www . at lanticayield.com/

[31] A. J. Gallego, E. F. Camacho, Adaptative state-space model predictive control of a parabolic-trough field, Control Engineering Practice 20(9) (2012) 904-911.

[32] D. di Ruscio, Model predictive control with integral algorithm: A simple mpc algo, Modeling, Identification and Control 34 (3) (2013) 119-129.

[33] A. Ruíz-Pardo, J. M. Salmerón, A. Cerezuela-Parish, A. Gil, S. Álvarez, L. Cabeza, Numerical simulation of a thermal energy storage system with pcm in a shell and tube tank, in: The 12th International Conference on Energy Storage, Innostock 2012, LLeida, 16th-18th May, 2012.

[34] R. Carmona, Análisis, modelado y control de un campo de colectores solares distribuidos con sistema de seguimiento en un eje., Ph.D. thesis, Universidad de Sevilla (1985).

[35] M. Berenguel, Contributions to the control of distributed solar collectors, Ph.D. thesis, Universidad de Sevilla (1996).

[36] M. Spoladore, E. F. Camacho, M. E. Valcher, Distributed parameters dynamic model of a solar fresnel collector field, in: Proceedings of the IFAC 18th World Congress. IFAC World Congress (18), no. 18, 2011, pp. 14784-14790.

[37] J. C. Butcher, Numerical Methods for Ordinary differential equations, 3rd Edition, Wiley, 2016.

[38] M. Robledo, J. M. Escano, A. Núnez, C. Bordons, E. F. Camacho, Development and experimental validation of a dynamic model for a fresnel solar collector, 18th IFAC World Congress.

[39] C. Afri, V. Andrieu, L. Bako, P. Dufour, State and param- 
eter estimation: A nonlinear luenberger observer approach, IEEE TRANSACTIONS ON AUTOMATIC CONTROL, 62(2) (2017) 973-979.

[40] T. Karvonen, Stability of linear and non-linear kalman filters, Master's thesis, Univerity of Helsinki (2014).

[41] E. F. Camacho, A. J. Gallego, Optimal operation in solar trough plants: a case study, Solar Energy 95 (2013) 106-117.

[42] L. Brus, D. Zambrano, Black-box identification of solar collector dynamics with variant time delay, Control Engineering and Practice 18 (2010) 1133-1146.

[43] E. F. Camacho, C. Bordons, Model Predictive Control, 2nd Edition, Springer Verlag, 2004.

[44] J. Rawlings, D. Mayne, Model Predictive Control: Theory and Design, Nob Hill Publishing, LLC, 2009.

[45] R. Findeisen, F. Allgöwer, An introduction to nonlinear model predictive control, Tech. rep., Institute for Systems Theory in Engineering, University of Stuttgart, (2006).

[46] R. Kalman, A new approach to linear filtering and predictions problem, Trans. ASME Jounal of Basic Engineering 82 (1960) 35-60.

[47] A. Romanenko, J. A. Castro, The unscented Kalman filter as an alternative to the EKF for nonlinear state estimation: a simulation case study, Computers and Chemical Engineering 28 (2004) 347-355.

[48] M. St-Pierre, D. Gringras, Comparison between the unscented kalman filter and the extended kalman filter for the position estimation module of an integrated navigation information system, IEEE Intelligent Vehicles Symposium 0-7803-8310-9/04 (2004) 831-835.

[49] L. Li, C. Hua, H. Yang, A new adaptive unscented kalman filter based on covariance matching technique, in: International Conference on Mechatronics and Control (ICMC), 2014. doi:10.1109/ICMC.2014.7231764.

[50] Y. Zhou, C. Zhang, Y. Zhang, J. Zhang, A New Adaptive Square-Root Unscented Kalman Filter for Nonlinear Systems with Additive Noise, International Journal of Aerospace Engineering (2015) 1-10.

[51] Y. Wang, Z. Qiu, X. Qu, An improved unscented kalman filter for discrete nonlinear systems with random parameters, Discrete Dynamics in Nature and Society (2017) 1-10.

[52] H. C. Hottel, A simple model for estimating the transmittance of direct solar radiation through clear atmospheres, Solar Energy 18 (1975) 129-134

[53] M. Paulescu, O. Mares, E. Paulescu, N. Stefu, A. Pacurar, D. Calinoiu, P. Gravila, N. Pop, R. Boata, Nowcasting solar irradiance using the sunshine number, Energy conversion and management 79 (2014) 690-697.

[54] U. Maeder, F. Borrelli, M. Morari, Linear offset-free model predictive control, Automatica 45 (2009) 2214-2222.

[55] D. Limon, I. Alvarado, T. Alamo, E. Camacho, Robust tubebased mpc for tracking of constrained linear systems with additive disturbances, Journal of Process Control 20 (2010) 248260.

[56] E. F. Camacho, M. Berenguel, F. R. Rubio, Advanced control of solar power plants, Springer Verlag, London, 1997.

[57] E. F. Camacho, M. Berenguel, F. R. Rubio, Application of a gain scheduing generalized model predictive controller to a solar power plant, Control Engineering Practice 2(2) (1994) 227-238. 